\title{
Moral dilemmas that matter
}

\author{
Kevin Kimble \\ Department of Philosophy, National Chung Cheng University, Taiwan
}

Email address:

kekimble@ccu.edu.tw

\section{To cite this article:}

Kevin Kimble. Moral Dilemmas that Matter. International Journal of Philosophy. Vol. 1, No. 2, 2013, pp. $29-37$.

doi: 10.11648/j.ijp.20130102.11

\begin{abstract}
One question that has been at the center of a lively debate among moral philosophers in recent years is the issue of what constitutes a genuine moral dilemma. Informally, a moral dilemma is a situation in which an agent must decide between two (or more) competing courses of action open to her, each of which has compelling moral considerations in its favor. One problem that arises with this formula is that whether a given situation counts as genuinely dilemmatic depends not only on the particular moral principles that are undergirded by particular moral theories, but also on the way in which the 'ought' operator is to be understood. This paper focuses on the latter issue. In what follows, I examine several contemporary accounts of moral dilemmas, briefly delineating the main logical options regarding how the 'ought' operator is to be understood in the definition of a dilemma. After elaborating on these different readings of the deontic operator and comparing them, I argue that cases of moral conflict qualify as genuine dilemmas on only one particular reading. This finding has significant implications regarding how we should understand moral dilemmas and what kinds of cases, if any, should count as genuine dilemmas. Thus, the main contribution of this paper is to clarify the notion of a genuine moral dilemma by making explicit possible and plausible meanings of the deontic operator. Only when this is done can various arguments for or against the existence of moral dilemmas be properly evaluated.
\end{abstract}

Keywords: Moral Dilemma, Deontic Logic, Ought, Moral Reasons

\section{Introduction}

One question that has been at the center of a lively debate among moral philosophers in recent years is the issue of what constitutes a genuine moral dilemma. Imagine that you are a surgeon on your way to the airport to catch a plane to your daughter's wedding. You excitedly hurry down the freeway at dawn on this glorious day-- a day that both you and she have been looking forward to for a long time. Perhaps you have not always been available to her when she has needed you; but you have promised her and reassured her time and again that you would be there for her this time, that you would be there to present her in marriage on this most important day. More than once have you assured her that nothing short of your own death or some incapacitating injury or illness could keep you from participating in this glorious event. But suddenly you see the only car ahead of you spin off the road and roll over several times. The car is on fire, and you hear a woman from inside the car screaming for help. It's early morning, no other cars are on the road, and there is nothing for several miles. (You left your cell phone at home since you are not on call and don't want to be disturbed.) You pull your car over to the side, run over to the burning car, and carefully pull the woman and her little boy out. You quickly assess the situation: they are both hurt badly, and there is a fair chance that the boy will suffer some permanent brain damage unless you perform an on the spot emergency medical procedure, for which you are eminently qualified. However, if you perform this procedure, you will miss the only flight that can get you to your daughter's wedding.

What should you do? On the one hand, it seems that there are compelling moral considerations in favor of your staying at the scene of the accident and helping the little boy. On the other hand, there appear to be weighty moral considerations which mandate that you continue on to the airport (and, of course, pull over at the nearest location to call for emergency help), so that you can show up as promised to your daughter's wedding. Is the situation you find yourself in here a real moral dilemma? You are faced with two choices to do two different things, each of which you morally ought to do, and yet given certain contingent features of the situation, it is not possible for you to do both. And many philosophers claim that these are precisely the ingredients that make up a moral dilemma.

Informally, then, a moral dilemma is a situation in which 
an agent must decide between two (or more) competing courses of action open to her, each of which has compelling moral considerations in its favor. The formal structure of a standard moral dilemma (SD) can be expressed in the following way. Where ' $\mathrm{O}$ ' represents the deontic operator (ought), ' $\varphi$ ' and ' $\psi$ ' represent distinct actions an agent $S$ may perform in one or more given sets of circumstances $\mathrm{C}$, and 'CC' represents the modal operator 'can', we will read ' $\mathrm{O}_{\mathrm{s}, \mathrm{c}}(\varphi)$ ' as ' $\mathrm{S}$ ought to do $\varphi$ in circumstances $\mathrm{C}$ ' and ' $\mathrm{C}_{\mathrm{s}, \mathrm{c}}(\varphi)$ ' as 'S can perform $\varphi$ in circumstances $\mathrm{C}$ '. Then the following set of sentences characterizes a genuine moral dilemma (SD):

$$
\begin{aligned}
& \mathrm{O}_{\mathrm{s}, \mathrm{c}}(\varphi) \\
& \mathrm{O}_{\mathrm{s}, \mathrm{c}}(\psi) \\
& \sim \mathrm{C}_{\mathrm{s}, \mathrm{c}}(\varphi \& \psi)
\end{aligned}
$$

One problem that arises with the use of this formula is that whether a given situation counts as genuinely dilemmatic depends not only on the particular moral principles that are undergirded by particular moral theories, but also on the way in which the 'ought' operator is to be understood. This paper focuses on the latter issue. The central task of this paper is to clarify the notion of a genuine moral dilemma by making explicit possible and plausible meanings of the deontic operator. Only when this is done can various arguments for or against the existence of moral dilemmas be properly evaluated. In what follows, I examine several contemporary accounts of moral dilemmas, briefly delineating the main logical options regarding how the 'ought' operator is to be understood in the definition of a dilemma. After elaborating on these different readings of the deontic operator in SD and comparing them, I argue that cases of moral conflict qualify as genuine dilemmas on only one particular reading. This finding has significant implications regarding how we should understand moral dilemmas and what kinds of cases, if any, should count as genuine dilemmas. ${ }^{1}$

There are a variety of cases of moral conflict that have been widely discussed by moral philosophers. To get started, I now briefly describe three standard cases that appear frequently in the literature on dilemmas. These will serve as a springboard for delineating the logical options regarding how the 'ought' operator is to be understood in

\footnotetext{
1 For the most part, the two predominant traditions in modern moral philosophy-- Kantianism and utilitarianism-- have tended to reject the possibility of moral dilemmas. While recognizing the existence of moral conflict and "apparent" dilemmas, they have thought either that at least one of the conflicting "ought" claims is not true, or else that the two claims do not really enjoin incompatible actions. In recent years, however, a number of moral philosophers have challenged this view by arguing that there are genuine moral dilemmas. Contemporary defenders of the traditional view have responded by offering several arguments which purport to establish the impossibility of dilemmas. I shall not directly enter into this debate here. The contribution of this paper is to make explicit various possible meanings of the deontic operator in order to clarify the conditions that constitute a genuine moral dilemma. Only when this is done will it be possible to give a proper evaluation of the major arguments for and against dilemmas.
}

our definition of SD.

\section{Agamemnon}

Agamemnon has a duty to carry out a military expedition against Troy, but his mission is being hindered by a goddess who requires the sacrifice of his daughter before she will grant him success. Agamemnon accepts that his obligation to complete the mission takes precedence over sparing his daughter, and so he sacrifices her. (To ensure that Agamemnon's commitment to his mission reflects a moral duty, we may assume that his expedition against Troy is the only way to prevent an otherwise certain and fatal offensive by the enemy against his own army and people.) Agamemnon has a moral obligation to protect his people and hence ought to do that which is necessary to meet this obligation-- namely, carry out his expedition against Troy. On the other hand, he also has an obligation to protect the life of his child, and hence ought not sacrifice her. But clearly Agamemnon cannot do both [1]. ${ }^{2}$

\section{Sophie's Choice [2]}

Sophie and her two children are imprisoned in a Nazi concentration camp, where a guard forces upon her the following choice. If she will select one of her children to be killed, the other will be allowed to live. If she refuses to choose, then both of the children will be killed. Sophie is morally obligated to protect the well-being of each of her children, and we may stipulate that the commitment to each is equally strong. Yet although she can save the life of either child, she can only do so by in effect "ordering" the death of the other. Either way, Sophie will end up doing something she ought not to do (consenting to the death of one of her children), thus failing in her obligation to protect the life of that child.

\section{Runaway Trolley}

Trolley scenarios such as this one abound in the literature $[3,4]$. Suppose that someone is driving a runaway trolley that branches ahead into two tracks, track \#1 that goes straight if the driver continues holding down on the lever, and track \#2 that veers left if he lets up on the lever. Unfortunately, if the driver goes straight he will run over a mother and her daughter, but if he goes left he will run over another mother and her daughter. Given the situation at hand, he ought not to go straight, but he also ought not turn left. Since there is no way for the driver to avoid both courses of action altogether, it appears that he is caught in a dilemma. $^{3}$

\footnotetext{
${ }^{2}$ In each of the cases I discuss in this section, there may be some minor variations between my accounts and the originals. Unless stated otherwise, references made throughout the text are to my versions of the examples.

${ }^{3}$ Notice that I have described the scenario in such a way as to make it invulnerable to the problems of killing versus letting die and the Doctrine of Double Effect. In typical trolley cases the moral agent is confronted with options that are not altogether on a par, e.g., if he does nothing the trolley proceeds on one track and kills someone, and if he performs a particular action the trolley turns onto another track and kills someone else. It might be argued that it would be better (morally) for the agent simply to do nothing and let the trolley remain on its current course than to actively cause
} 


\section{Contemporary Accounts of Moral Dilemmas}

Clearly the above cases depict genuine moral conflicts of one sort or another, but in order to determine whether they qualify as dilemmas according to our definition captured by $\mathrm{SD}$, we need to work toward a more fine-grained understanding of just what we mean by "ought". The moral notion of "ought" has several distinct shades of meaning. We might follow W. D. Ross and distinguish between prima facie and actual or all-things-considered moral duties. A prima facie "ought" is that quality an act has "in virtue of being an act which would be a duty proper if it were not at the same time of another kind which is morally significant" [5]. Any particular act falls under various descriptions, and a prima facie duty is what one ought to do ceteris paribus, or in the absence of other competing moral considerations. In other words, there exists some moral reason to perform the action. This is roughly equivalent to what Sinnott-Armstrong calls a "possibly overridden moral requirement" [6,7]. An actual duty, on the other hand, is that which is morally obligatory in a particular situation all things considered. The particular action is supported by the strongest moral reasons. An action $A$ is morally required all things considered if on balance, in light of all the morally relevant and competing factors, $A$ is what one ought to do in a given circumstance.

Situations which involve conflicting prima facie reasons for performing some action (or actions) are often resolvable in a manner which allows the agent to do what he is morally required to do without violating any competing (actual) obligations in the situation. So defining the ought operator of SD in terms of prima facie moral reasons does not capture the intuitive notion of a genuine moral dilemma. A number of philosophers interpret the operator using the all-things-considered (hereafter abbreviated ATC) description of "ought," but it is important to point out that $A T C$ "oughts" can be understood in slightly different ways. For example, David O. Brink construes moral dilemmas as competing $A T C$ obligations in the following way:

One is under an all-things-considered obligation to do $x$ just in case one is under a prima facie obligation to do $x$, and there is no greater, simple or complex, competing prima facie obligation one is under [8].

$\mathrm{He}$ further clarifies this notion of "all-things-considered" obligations by introducing the notion of undefeated moral reasons:

But prima facie obligations can be, and often are,

the death of a person by turning the trolley. It might further be argued that turning onto another track and killing the person(s) on that track (as opposed to letting the trolley continue on its natural course) is an intended means to a particular end, and that such actions are generally not permissible. My scenario circumvents such difficulties because both of the alternatives that are open to the driver involve actively doing some action, and each action has parallel consequences that are brought about in the same manner. defeated by other, weightier obligations, individually or in concert... an all-things-considered obligation is an undefeated prima facie obligation... a moral factor $\mathrm{F}$ is undefeated if 1) there are no competing moral factors, 2) there are competing factors that cancel each other out, or 3) competing factors not canceled out do not override F's support for x [8].

Brink's suggestion is that an "ought" is an $A T C$ obligation if and only if it is not ultimately overridden by other moral considerations. ${ }^{4}$ This account bears a strong affinity to Walter Sinnott-Armstrong's distinction between (possibly) overridden, non-overridden, and overriding moral requirements [6,7]. When moral reasons or "oughts" conflict but neither overrides the other, then while clearly neither is overriding, it will also be the case that neither is overridden. The competing "oughts" constitute non-overridden requirements or obligations. It is competing non-overridden "oughts" that are thought to generate real moral dilemmas. Because of the ambiguity of the term "all-things-considered" (ought) as it is used in the literature on moral dilemmas, Sinnott-Armstrong avoids using the term altogether. In a similar vein, in his discussion of $A T C$ “oughts" Terrance McConnell writes:

If the situation is genuinely dilemmatic, then one is presented with two conflicting ought-claims and no further moral consideration is relevant to resolving the conflict. By contrast, a situation is merely apparently dilemmatic if two ought-claims conflict, but there are overriding moral reasons for acting on one rather than the other [9].

The language suggests that McConnell is thinking of "ought" in much the same way as are Brink and Sinnott-Armstrong. In a more recent article, McConnell explicitly defines moral dilemmas in terms of "all-things-considered" oughts, which for him just are non-overridden moral reasons [10].

On the other hand, philosophers such as Gowans and Rescher seem to apply the term "all-things-considered" strictly to overriding "oughts" $[11,12]$. One might argue that to say that all-things-considered one ought to perform a certain action is to answer the question "What from a moral point of view should I do in this situation?" Asking what I ought (all-things-considered) to do is sort of like asking what would be the best thing for me to do, that is, what one thing should I choose to do in this situation; and such questions imply that there is at most one thing which I ought to do. ${ }^{5}$ Perhaps something akin to this is what philosophers such as Gowans and Rescher have in mind.

\footnotetext{
4 Although there is arguably a (technical) distinction to be made between the meaning of "ought" and the meaning of "obligation" as they are sometimes used in ethical contexts, I shall throughout this thesis, unless otherwise stated or implied, simply take "obligation" and "moral requirement" to be nominative forms of the verb "ought".

5 This insight was suggested to me by Richard Lee in personal correspondence.
} 
From a moral point of view, if there is one best thing that I ought to do in a certain situation, then the moral considerations for that action would override all moral considerations for competing actions.

Dilemmas involving conflicting overriding moral obligations are ruled out by definition. And if all-things-considered "oughts" are defined in this way, then within the structure of SD they too rule out the possibility that there be any more than one such "ought" in a given situation. So interpreting the operator in (SD) in terms of an $A T C$ "ought" in this sense rules out moral dilemmas for the same reason that using the operator to designate an overriding "ought" rules them out. If what I should do "all-things-considered" is by definition just one thing, then dilemmas are of course impossible. So our three cases described above could not constitute genuine dilemmas given such a reading of SD. Each example could then be explained in various ways, depending on the particular moral theory appealed to. If the only way Agamemnon can successfully lead his troops to victory is by sacrificing his own daughter, then such a condition might constitute a qualification on his duty as commander. Or the prohibition against intentionally killing an innocent civilian might outweigh his obligation to carry out the expedition. On the other hand, certain utilitarian theories might dictate that Agamemnon's decision to continue with the military campaign overrides the prohibition against killing innocent people by promoting the greatest overall good (e.g. by saving many of Agamemnon's people). In any case, Agamemnon could not have two overriding mandates. With regard to Sophie's Choice, if the dilemma involves choosing one child to die over the other, then perhaps she can escape between the horns by remaining silent. Or, if the situation is construed as a conflict between remaining silent and sending both children to their deaths versus choosing one to die and one to live, some will claim that taking the latter alternative overrides the former, for Sophie prevents one child from being killed (assuming, of course, that the soldiers keep their word). Others will claim the reverse-that Sophie's non-involvement would have been morally superior to the act of selecting one of her children to die. Finally, in Runaway Trolley, where the choices are completely symmetrical, defenders of the "overriding" sense of "ought" will point out that there is nothing which the driver ought to do all-things-considered, for there is no one action in the situation which morally outweighs all the others. The point is that in all these cases there are various options open to those who interpret 'ATC ought' as overriding and hence wish to deny the reality of moral dilemmas.

If interpreting the deontic operator employed in SD in the sense of "overriding ought" rules out dilemmas by definition, then on such an account one need not appeal to deontic principles in an attempt to refute SD. A much simpler argument will do: on the proposed definition of 'ATC ought,' given two distinct morally competing actions $A$ and $B$, an agent ought to do at most one action; since $A$ and $B$ are two distinct actions, it just follows from this that $\sim\left[\mathrm{O}_{o}\right.$ (A) \& $\left.\mathrm{O}_{o}(\mathrm{~B})\right]{ }^{6}$. So given such a reading of the deontic operator, traditional anti-dilemma arguments (which employ various deontic logical principles) would simply constitute an unnecessary move in a strategy to undermine the existence of moral dilemmas, since dilemmas are already effectively ruled out in their account of SD.

What about construing "all-things-considered" in the sense of non-overridden or undefeated moral reasons (e.g. Brink, McConnell, Sinnott-Armstrong)? Since this reading of the "ought" operator allows for the possibility of moral conflicts or dilemmas of this type, then if such conflicts are real, traditional anti-dilemma arguments can perhaps offer insight into how certain deontic principles fail (on this construal of "ought"); or given that these deontic principles are valid under the ' $\mathrm{O}_{\mathrm{n}}$ ' reading of $\mathrm{SD}$, the arguments might reveal some way in which the proposed account of moral conflicts or dilemmas is implausible.

Thus far we have distinguished three different and important senses of the "ought" operator. We may catalogue these as follows:

$\mathrm{O}_{p}$ (PMR) There is a prima facie moral reason(s) for $S$ to do $A$ in $C$

$\mathrm{O}_{\mathrm{o}}$ (OMR) There is an overriding moral reason(s) for $S$ to do $A$ in $C$

$\mathrm{O}_{n}$ (NMR) There is an undefeated or non-overridden moral reason(s) for $S$ to do $A$ in $C$

We have seen that Brink, Sinnott-Armstrong, and others claim that the sense of "ought" most relevant to the problem of moral dilemmas is "ought" understood in the sense of (NMR). Sinnott-Armstrong, for example, employs (NMR) in formulating his definition of a moral dilemma as: i) there is a (prima facie) moral requirement for an agent to adopt each of two alternatives, ii) neither moral requirement is overridden in any relevant way, iii) the agent cannot adopt both alternatives together, and $i v$ ) the agent can adopt each alternative separately [6]. ${ }^{7}$ He favors this way of construing moral dilemmas because a quandary involving two conflicting non-overridden moral requirements would be "irresolvable." As has been discussed much in the literature, the nature of this irresolvability can take two forms. There may be cases involving symmetrically structured conflicting claims, (allegedly) as in the examples of Sophie's Choice, Runaway Trolley (original), or in a case which is the moral counterpart to Buridan's Ass. On the other hand, some dilemmas may involve moral claims of differing types where it is impossible or inappropriate to "weigh" one

\footnotetext{
${ }^{6}$ Henceforth I shall use ' $\mathrm{O}_{n}$ ' to refer to the operator interpreted as non-overridden or undefeated oughts/ obligations, and ' $\mathrm{O}_{o}$ ' to refer to the overriding sense of ought.

${ }^{7}$ For Sinnott-Armstrong, an alternative action is a moral requirement "if and only if it would be morally wrong not to adopt that alternative if there were no moral justification for not adopting it" (Moral Dilemmas, p. 12).
} 
claim against the other. ${ }^{8}$ In such cases the moral "oughts" are said to be incommensurable. With both types of irresolvability, the "oughts" have equal or incomparable moral strength and so no moral considerations could ultimately favor one action over the other.

Similarly, Brink explicates his definition of a dilemma (involving competing all-things-considered or undefeated obligations) in terms of the notion of irresolvability. A moral conflict is a genuine dilemma just in case it is insoluble; and a conflict is insoluble if and only if it involves metaphysical equipollence. According to Brink, there are two brands of equipollence-- narrow and broad. A dilemma may be described as narrowly equipollent when the alternatives involved reflect symmetrically structured conflicting moral claims, as when the weighing of moral options seems to result in a tie (e.g. the moral counterpart to Buridan's Ass). Broad equipollence parallels (roughly) the notion of incommensurability sketched above [8]. ${ }^{9}$ This type of equipollence exists in conflict situations which employ differing scales or dimensions of assessment. Brink contends that genuine dilemmas require broad equipollence as a minimum. If two conflicting moral claims involve broad equipollence, each of those claims may be said to be undefeated or non-overridden with respect to each other.

\section{The Failure of the Contemporary Accounts}

\subsection{A Closer Look at Some Examples of Moral Conflict}

One problem, however, in interpreting SD in terms of undefeated or non-overridden "oughts" is that this construal of the deontic operator is not the only or even primary sense of "ought" that matters to people in situations involving moral conflict. That is, moral agents are not merely concerned with the question of whether their alternatives are overriding, non-overridden, or undefeated; what they often want to know is whether they will be doing something morally wrong in those particular circumstances no matter what course of action they take. Moral agents want an answer to this question: "Given that I have to

\footnotetext{
${ }^{8}$ The predicament of one of Sartre's students is sometimes cited as an example of this sort of dilemma. Sartre reported that a student in occupied France came to him asking whether it was his duty to join the Free French forces and avenge his brother's death or stay home and care for his dependent mother. The choices at hand allegedly involved a weighing of incommensurable values. See Jean-Paul Sartre, "Existentialism is a humanism," trans. P. Mairet, in W. Kaufmann (ed), Existentialism from Dostoevsky to Sartre. New York: Meridian, 1957, pp. 295-296.

${ }^{9}$ Here Brink makes a further distinction (not crucial for our purposes) between moral actions or claims that are strongly incommensurable versus actions or claims that are weakly incommensurable. Acts $x$ and $y$ are strongly incommensurable just in case no token of type $x$ is comparable with any token of type $y$; and $x$ and $y$ are weakly incommensurable just in case some (but not all) tokens of type $x$ are not comparable with some tokens of type $y$.
}

choose between two conflicting actions $A$ and $B$, and given that the moral reasons or considerations for doing each of the actions are weighty or compelling, will I be doing something morally wrong in this situation by failing to do $A$ or by failing to do $B$ ?" This question is clearly distinct from the question of whether a given course of action is morally overridden, overriding, non-overridden, etc.; and in fact the two questions may have quite different answers.

In Runaway Trolley, recall that the track branches ahead in two directions-- track \#1 goes straight if Gus, who is maneuvering the trolley, continues holding down on the lever, and track \#2 takes him left if he lets up on the lever. Now perhaps, to use David O. Brink's terminology, Gus has undefeated moral reasons for not turning left and undefeated moral reasons for not going straight; or to use Sinnott-Armstrong's language, he has a non-overridden moral requirement not to turn left and a non-overridden moral requirement not to go straight $[6,8]$. But that is not the same thing as saying that Gus has definitive moral reasons in the circumstances, say, for not turning left-- i.e., that it would be morally wrong in the circumstances for him to turn left. And it seems to me that an agent faces a genuine moral dilemma if and only if something like the following is true: each of the competing "oughts" or requirements is morally compelling or definitive in the sense that it would be morally wrong for the agent in those circumstances to refrain from performing them. Why should the fact that two competing actions involve moral requirements in Sinnott-Armstrong's sense make the situation in question a moral dilemma unless it would be morally wrong in that situation not to perform either of those actions? Such non-overridden alternatives might make the situation a sort of "dilemma of decision-making" on a par with "Buridan's Ass", but that would not necessarily make it a moral dilemma. If the "oughts" are not morally compelling or definitive in the situation, then the mere fact that they are non-overridden does not seem to be sufficient in and of itself to call the situation a real moral dilemma. More will be said on this shortly.

The issue of whether moral requirements or reasons are overridden or not, and whether conflicts are "irresolvable" or "insoluble," is logically distinct from the question of whether or not there are or can be real moral dilemmas. Whether an action or moral ought is "non-overridden" or a pair of conflicting actions "insoluble" in a given set of circumstances is not necessarily what makes the action(s) morally obligatory, morally permissible, or morally wrong in those circumstances. It seems possible that a moral agent might find herself in a situation in which she is faced with deciding between two conflicting moral actions or alternatives, one of which clearly overrides the other, but regardless of which course of action she takes she will be doing something morally wrong in that situation. The definitive moral "rightness" or "wrongness" of a particular concrete act or pair of conflicting actions seems especially relevant to whether or not the situation counts as a dilemma. In what follows I shall argue that the popular criterion of 
conflicting undefeated or non-overridden moral reasons or obligations is neither necessary nor sufficient for a situation to qualify as genuinely dilemmatic. ${ }^{10}$

\subsection{Competing Non-Overridden Moral Reasons or Requirements Are Not Necessary for Dilemmas}

I will now argue that interpreting SD in terms of undefeated or non-overridden reasons or requirements fails to adequately characterize the structure of a moral dilemma. First, if we employ (NMR) as the meaning of the deontic operator, SD so interpreted is not necessary for dilemmas. (Corresponding to the way I have chosen to symbolize the deontic operator for this type of ought, let's call this reading of a standard dilemma $\mathrm{SD}_{\mathrm{n}}$.) Consider a modified trolley scenario (Runaway Trolley II) in which Gus runs over ten people if he goes straight and runs over nine people if he goes left. Assuming that numbers do matter, perhaps Gus ought all-things-considered to let up on the lever and turn left. ${ }^{11}$ Although turning left does indeed have the overriding moral considerations in its favor, it seems incredible to me to suppose that if this situation is not a moral dilemma, simply adding one more person to the left track would make it a moral dilemma. But that is what $\mathrm{SD}_{\mathrm{n}}$ implies. And if having ten persons on each track does constitute a real moral dilemma, then (I think) it does so in virtue of the fact that Gus' turning either way (and killing ten people) would be morally wrong. (Such a moral judgment would hold in any ethical system which includes, for example, a precept like "It is always morally wrong to kill an innocent person when the killing could have been avoided.") So if one person is subtracted from the left track, and Gus runs over nine people instead of ten, then although Gus perhaps fulfils an overriding moral requirement, he nevertheless performs an action that is morally wrong in the situation. (Subtracting one person would not change the fundamental wrongness of the act.) If the original "symmetric" trolley scenario is a genuine moral dilemma, then so is our modified scenario, where Gus also ends up doing something morally wrong no matter what course of action he takes-- and thus his situation remains truly dilemmatic, even though it does not involve a pair of "oughts" that are non-overridden.

In the original Runaway Trolley, what makes the alleged dilemma "irresolvable" (in the sense of there being no morally best option) is the fact that neither action is overridden by the other. But if the scenario truly does depict a moral dilemma, then what makes each of the (non-overridden) "oughts" or requirements morally

\footnotetext{
${ }^{10}$ Sinnott-Armstrong does delineate several other types of moral conflicts or dilemmas ("Moral dilemmas and rights", p. 53-61), including what he calls a moral wrongs dilemma. But the examples he gives of each of these types all include the features of non-overridden moral reasons and irresolvability as defined above. So in the end he still opts for conflicts employing (NMR) as defining the only genuine type of dilemma.

${ }^{11}$ For a contrary opinion, see John Taurek, "Should the numbers count?", Philosophy and Public Affairs, Vol. 6, 1977, pp. 293-316.
}

compelling is not the comparative moral weight assigned to them, but rather the fact that each action possesses certain definitive right-making characteristics (or, alternatively, that failure to perform each action possesses wrong-making characteristics)-- features which make each of the "oughts" morally compelling and thus would make it morally wrong in those circumstances not to perform the actions. Given the supposition that taking either track would be morally wrong, it is difficult to see how adding or subtracting a person from either of the tracks would significantly alter the moral rightness or wrongness of Gus' particular action. (Changing the numbers on the track does affect the moral status of his action in one way, by making it overriding or overridden with respect to other alternatives in the situation.) If Gus takes the left track and runs over nine people, then the consideration of whether, say, there were ten persons on the straight track rather than nine will determine whether the action is overriding, and will therefore affect the moral status of Gus' action in that sense, but it will not remove the fundamental or definitive moral wrongness of his particular action. ${ }^{12}$ These senses of "ought" are not mutually exclusive-- an action can be overriding and be an instance of (OMR), yet at the same time be definitively morally wrong. The upshot of this whole discussion is that $\mathrm{SD}_{n}$ by definition rules out as dilemmatic any moral conflict that does not involve competing non-overridden or incommensurable moral considerations. This seems too restrictive.

We can illustrate the problem further by comparing two slightly modified versions of another kind of scenario somewhat analogous to trolley cases. Let's call this next case Wedding Singer I. You are a highly talented singer who has promised to a life-long friend that you will perform in his wedding this summer in Chicago (on such and such a date). You have another life-long friend to whom you have made this same promise, reassuring him countless times, and when he approaches you with the exact date of the wedding, you mark it down in a different calendar from the one you marked when you noted your other friend's wedding. Being the busy person you are, each morning you check both calendars, and one Saturday morning you discover that you have inadvertently obligated yourself to perform in these two weddings that same afternoon-- one in Chicago and the other in New York. Since neither party is willing to release you from your obligation (each insists that you keep to your promise; after all, you are life-long

\footnotetext{
${ }^{12}$ Here it appears that the action of taking the left track and killing nine people is the very same action as taking the track which results in the lesser number of deaths. If so, we are faced with the problem of just how one and the same action can be both right and wrong, since this seems to be incompatible with a certain version of the consistency thesis, or $\sim[\mathrm{O}(\mathrm{A}) \&$ $\mathrm{O}(\sim \mathrm{A})]$. But notice that in this case the sense in which he both "ought" to perform the action and "ought not" perform the action involve slightly different senses of "ought." The more difficult problem is making sense of the denial of the consistency thesis when both occurrences of the operator carry the same meaning.
} 
friends), it appears that you are morally obligated to sing in both weddings. The moral reasons in favor of each alternative are equally compelling, and it is reasonable to think that backing out of either promise would be morally wrong in these circumstances.

Now let's modify the case slightly: in Wedding Singer II, suppose that originally you agreed to sing in two weddings back to back in Chicago (one at 3:00 and the second at 6:00), alongside your other promise to perform at a wedding in New York on the same day. Now you have overriding moral reasons for performing at the two weddings in Chicago, while the moral considerations that weigh in favor of your keeping your promise to sing in New York are overridden. Yet it is still true that you have definitive moral reasons for going to New York, for to back out on your promise would be morally wrong in the situation; hence you face a genuine moral dilemma. ${ }^{13}$ Our comparison of these two cases suggests that the relevant feature of a truly dilemmatic situation is not Brink's "equipollence" or Sinnott-Armstrong's condition that the alternatives in the situation be "non-overridden", but rather the compelling nature of the competing moral considerations or "oughts" that are involved. This conclusion is also supported by our previous comparison of the runaway trolley examples.

Examples such as Agamemnon also show that non-overriddenness is not necessary for dilemmas. Some of the most plausible cases for dilemmas are cases where the "oughts" clearly are not symmetric. Let's consider yet another case, Armageddon. ${ }^{14}$ The President of the United States has received word from top NASA scientists that a large asteroid is headed for the earth and will crash into the Atlantic Ocean with an impact so great that most of the population of the western hemisphere will be wiped out. The only way to prevent the catastrophe is to break up the asteroid by detonating a nuclear bomb that must be placed at a certain strategic location in a large crater near the center of the asteroid. The only astronaut who is qualified to maneuver a spacecraft through the asteroid, land the ship, and place the nuclear device in the required location is the President's own son. The mission has a very good chance of success, but the President's son will only agree to it on the condition that he be allowed to flee a safe distance from

\footnotetext{
${ }^{13}$ Of course, opponents of dilemmas argue that such "promise" scenarios do not depict moral dilemmas at all, and they sometimes appeal to various principles that show how conflicting promises may be resolved (e.g., Alan Donagan, "Consistency in rationalist moral systems", Journal of Philosophy (81), 1984, pp. 291-309). But there seem to be problems with adequately articulating such principles. In any case, as in my trolley examples, I am not arguing that such situations are in fact dilemmatic; all that I am suggesting is that such situations are plausibly taken by some to be instances of genuine moral dilemmas, and so any adequate account of what a dilemma is should not ipso facto rule out cases of this type which do not happen to involve non-overridden moral "oughts".

${ }^{14}$ As the label suggests, this example is adapted from the basic story line of the movie Armageddon, although with substantial modifications.
}

the asteroid before the President detonates the bomb. Now the President clearly has a moral duty to do whatever he can to secure the safety of the free world. But he has been reliably informed by the NASA scientists that, unfortunately, once the bomb is planted in the crater there will be no time left to let the astronaut flee to safety (the required time interval would put the asteroid too close to the earth for the bomb to have any effect). The only way for the President to save the free world is to deceive the astronaut and "agree" to his terms, sending him up to the asteroid with a bomb secretly hidden inside the ship-- a bomb that is set to detonate automatically once the ship reaches the desired location on the asteroid. Now it seems plausible to say that while there are overriding moral considerations which support the President's plan to protect western civilization, it would still be morally wrong in the circumstances for the President to deceive his son and sacrifice his life against his will. If so, then the President is clearly caught in a moral dilemma; but since this situation does not (it seems to me) involve competing "oughts" or moral considerations each of which are undefeated or non-overridden, scenarios like Armageddon would not count as a dilemma on the standard definition expressed by $\mathrm{SD}_{\mathrm{n}}$. What cases like this show is that the standard condition of non-overriddenness laid out by philosophers such as Brink, Sinnott-Armstrong, and McConnell is not necessary in order for there to be genuine moral dilemmas.

We could also modify Runaway Trolley and Wedding Singer II once more to generate a different kind of moral dilemma that would fail to qualify as such under $\mathrm{SD}_{\mathrm{n}}$. Imagine that unbeknownst to us Gus possesses certain violent tendencies and kidnaps his six most despised enemies, tying five of them down to track \#1 and tying the other one to track \#2. The remainder of the scenario plays out just like the original. Now even though one action clearly (morally) overrides the other action, either way Gus goes he will be doing something morally atrocious. It appears that he is caught squarely in a moral dilemma despite the fact that turning left involves no non-overridden moral considerations. Turning to our other example, suppose that the wedding singer is angry at his friends and, in order to get back at them, makes promises to them that he has no intention of fulfilling. Even though his obligation to go to New York is overridden by his obligation to go to Chicago (where he will perform in two weddings), the wedding singer is still morally wrong for breaking his promise to the friend in New York. These situations are instances of what Aquinas calls "perplexity secundum quid"-- a moral dilemma or "perplexity" that arises as a result of an agent's violating a moral precept himself $[13,14]$. If the conditions set forth in $\mathrm{SD}_{n}$ were necessary in order for a situation to count as a true dilemma, it would entail the non-existence of many secundum quid dilemmas (all those involving overriding moral reasons)-- situations which friends and foes of dilemmas alike might wish to count as truly dilemmatic [15].

This example of a dilemma secundum quid is instructive, 
because it demonstrates that having non-overridden or undefeated moral "oughts" (NMR) is not an essential ingredient of a genuine moral dilemma. For example, what makes both courses of action that are open to Gus (the maneuvering of the trolley left or straight) morally wrong in the situation, and the refraining from the respective actions morally obligatory, are salient moral features of the actions themselves-- their definitive right-making (or wrong-making) characteristics-- and not the relative moral weight assigned a particular action relative to some other action or actions. If defenders of the $\mathrm{SD}_{n}$ account of dilemmas wish to stipulate that any situation that satisfies the conditions of $\mathrm{SD}_{n}$ or is a conflict secundum quid counts as a dilemma, one wonders whether there isn't something wanting in their original account. We ought to strive for a single account of dilemmas along with one reading of the deontic operator that captures both intuitive notions of dilemmas simpliciter and dilemmas secundum quid. The preferred definition should also make room for other conflict situations involving overriding and overridden obligations or reasons, reflecting the possibilities drawn out in the modified scenarios discussed above.

\subsection{Competing Non-Overridden Moral Reasons or Requirements Are Not Sufficient for Dilemmas}

Neither does $\mathrm{SD}_{n}$ delineate sufficient conditions for the existence of moral dilemmas. We can easily imagine cases which involve non-overridden moral considerations (and are irresolvable) and yet where it would not be appropriate to call those cases dilemmas at all. Suppose that in Charity, a philanthropist has vowed to give a sum of money to some charity that comes to his door by 10 a.m. today, and he has just enough money to give to one charity only. Two charities come knocking on his door at 10 a.m.. Suppose that the two charities serve the same cause and thus are similar enough to give the philanthropist equal moral reasons for giving the sum of money to each. Neither option is morally overridden by the other, but the philanthropist cannot give to both. Furthermore, each of the competing actions also satisfies Sinnott-Armstrong's and Brink's definition of a moral requirement or obligation, for had either one of the charities not showed up at 10 a.m., the philanthropist would have been morally wrong to withhold giving the sum of money to the other charity. He is clearly faced with two conflicting and undefeated moral "oughts", and hence $\mathrm{SD}_{n}$ is satisfied. ${ }^{15}$ Yet one should be reluctant to call this scenario a real moral dilemma; in these circumstances our philanthropist does not experience real moral tension, because he is not confronted with the

\footnotetext{
15 This type of case satisfies both Sinnott-Armstrong's and Brink's conditions of a moral dilemma. See Sinnott-Armstrong, Moral Dilemmas, p. 12; "Moral dilemmas and rights", p. 49; and Brink, pp. 102-103. Recall that for both Sinnott-Armstrong and Brink an alternative is a moral requirement if and only if it would be morally wrong not to adopt that alternative if there were no moral justification for not adopting it.
}

inevitability of doing something morally wrong. He merely promised to give money to some charity, and so he is perfectly free to choose which of the two.

Consider one final scenario: in Coffee Shop, Slim's doctor has put Slim on a rather strict high-fat high-carbohydrate diet for certain health reasons. Part of the diet requires Slim to eat at least one rich freshly baked pastry for breakfast every morning. Following the diet is very important for Slim's health, and so he promises both his family and his doctor that he will stick to it each day. On the first morning of his diet Slim walks into a coffee shop to meet a friend (everyone knows that this particular shop is the only place for hundreds of miles where one can get freshly-baked pastries), and discovers that due to the high demand for freshly-baked pastries, the owner of the coffee shop prohibits each of his customers from eating more than one pastry from his shop per day. When Slim enters the coffee shop on this particular morning, there are only two pastries left, a donut and a cinnamon roll. Now it appears that Slim has moral reasons for eating each of the pastries, and the considerations in each case are equal. (Eating both of the pastries is not an option.) Thus he has an undefeated or non-overridden moral reason to eat the donut and an undefeated or non-overridden moral reason to eat the cinnamon roll. ${ }^{16}$ So the conditions described by $\mathbf{S D}_{\mathrm{n}}$ are satisfied, and accordingly Slim confront a moral dilemma. But certainly it is stretching things a bit to think that Slim really faces a dilemma. For surely he could simply choose to eat the donut, or choose to eat the cinnamon roll-- or perhaps, if he is sadly too much like Buridan, flip a coin to decide which-- and then walk out of the store without even giving it a second thought as to whether he had done anything morally wrong. So it looks as though it is not the particular feature of a pair of conflicting moral actions' being non-overridden that makes such a situation a moral dilemma. A situation's involving competing non-overridden or undefeated moral reasons or "oughts" is not sufficient to generate a real dilemma.

\section{Definitive Moral Reasons}

The above criticisms suggest that we need a broader definition of the "ought" operator which can accommodate dilemma situations like the ones discussed above that are nonetheless ruled out by $\mathbf{S D}_{n}$. We need a construal of the deontic operator that will include all and only those situations that captures our intuitive notion of a dilemma. My proposal is that we define ' $\mathrm{O}$ ' in terms of the definitive or binding nature of a moral ought or obligation in a given situation. An agent $S$ definitively (morally) ought to

\footnotetext{
16 Once again, each of these choices or actions qualifies as a moral requirement on Sinnott-Armstrong's and Brink's definitions, because if there were only one or the other of the pastries left in the store, Slim would be violating the requirements of the diet and breaking his promise by not eating it (see previous footnote).
} 
perform action A in circumstances $C$ if and only if $S$ 's refraining from doing $A$ in $C$ would be morally wrong. And $S$ definitively ought not to perform $A$ in $C$ if and only if doing $A$ in $C$ would be morally wrong. In other words, an action (or requirement) $A$ is morally definitive for $S$ in $C$ (or $S$ has morally definitive reasons for doing $A$ in $C$ ) if and only if it would be morally wrong for $S$ not to do $A$ in $C$. We can now add a fourth sense of 'ought' to our original three:

(DMR) There is a definitive moral reason(s) for $S$ to do $A$ in $C$

This gives us a fourth interpretation of the deontic operator. $\mathrm{O}_{\mathrm{d}}(\mathrm{A})$ reads " $A$ is a definitive or binding moral obligation for $S$ in $C$ ", " $S$ definitively ought (has a definitive moral reason) to do $A$ in $C$ ", or " $S$ is definitively morally required to do $A$ in $C$." Accordingly, we can employ (DMR) in our definition of a standard moral dilemma and call the revised definition $\mathrm{SD}_{d}$. In terms of the formalization of a moral dilemma we started out with (based on our general definition of a moral dilemma given in section 1), we can write:

$$
\begin{aligned}
& \mathrm{O}_{d[\mathrm{~s}, \mathrm{c}]}(\varphi) \\
& \mathrm{O}_{d[\mathrm{~s}, \mathrm{c}]}(\psi) \\
& \sim \mathrm{C}_{\mathrm{s}, \mathrm{c}}(\varphi \& \psi)
\end{aligned}
$$

$\mathrm{SD}_{d}$ captures the notion of a genuine moral dilemma more adequately than $\mathrm{SD}_{n}$ does.

\section{Conclusion}

The nuanced distinctions we have been discussing, involving how the "ought" operator is to be understood, are clearly significant in affecting our judgments as to the kinds of cases of moral conflict that properly count as genuine moral dilemmas. If there exist real moral dilemmas, such situations will be captured by $\mathrm{SD}_{d}$. That is because, as I have argued, SD captures our intuitive notion of a moral dilemma only when interpreted in terms of the definitive sense of "ought". Speaking of the definitive "rightness" or "wrongness" of acts done in concrete circumstances seems to more adequately pinpoint the crucial element which makes a situation truly dilemmatic. $S$ is in a moral dilemma if and only if $S$ is confronted with two competing definitive moral requirements in $C$ (or alternately, $S$ has definitive moral reasons for performing each of two competing actions in $C$ ). There are, of course, questions that remain regarding the nature of definitive ought claims and what their truth-makers are. It is not open to one to analyze DMR in terms of one or more of the other three notions of moral reasons; otherwise we will be faced with the original problems that beset the account of moral dilemmas which relied on those notions. Rather, it seems more likely that we will have to look to the resources of particular moral theories to shed light on the nature of definitive moral reasons.

\section{Acknowledgements}

I would like to thank Richard Lee for helpful comments and discussion that led to a much improved manuscript.

\section{References}

[1] Aeschylus, Agamemnon. Trans. Eduard Frankel. Oxford: Clarendon Press, 1950, pp. 160-217.

[2] William Styron, Sophie’s Choice. NY: Bantam Books, 1980.

[3] John M. Fischer and Mark Ravizza (eds), Ethics: Problems and Principles. Orlando, FL: Harcourt Brace Jovanovich, 1992, pp. 2-12.

[4] Judith Jarvis Thomson, "Killing, letting die, and the trolley problem," in Fischer and Ravizza, 1992, pp. 69-77.

[5] William D. Ross, The Right and the Good. Oxford: Clarendon Press, 1930, pp. 18-20. A substantive discussion of this distinction is found in his work.

[6] Walter Sinnott-Armstrong, Moral Dilemmas. New York: Blackwell, 1988, pp. 12-29.

[7] Sinnott-Armstrong, "Moral dilemmas and rights," in Homer E. Mason (ed), Moral Dilemmas and Moral Theory. NY: Oxford University Press, 1996, pp. 48-51.

[8] David O. Brink, "Moral conflict and its structure," in Mason, 1996, pp. 102-107.

[9] Terrance McConnell, "Moral dilemmas and consistency in ethics", in Christopher Gowans (ed), Moral Dilemmas. New York: Oxford University Press, 1987, p. 154.

[10] McConnell, "Moral residue and dilemmas," in Mason, 1996, p. 36.

[11] Christopher Gowans, "The debate on moral dilemmas", in Gowans, p. 27.

[12] Nicholas Rescher, Ethical Idealism. Berkeley: University of California Press, 1987, p. 41.

[13] St. Thomas Aquinas, Summa Theologiae, I-II, 6, II-II, 62,2, trans. Thomas Gilby, New York: McGraw Hill, 1970.

[14] Aquinas, de Veritate, 17,4, trans. R.W. Mulligan, Chicago: Henry Regnery Co., 1954.

[15] Alan Donagan, "Consistency in rationalist moral systems," Journal of Philosophy (81), 1984, pp. 305-308. 